\title{
Multicystic peritoneal mesothelioma: not always a benign disease
}

\author{
Ashish Singh ${ }^{1}, \mathrm{MD}$, Parangama Chatterjee ${ }^{2}, \mathrm{MD}$, Mahesh Chandra Pail ${ }^{1}, \mathrm{MD}$, Raju Titus $\underline{\text { Chacko }}^{1}$, MD
}

\begin{abstract}
Mesothelioma is a slow-growing insidious lesion of neoplastic aetiology arising from the pleural, peritoneal or pericardial mesothelium. It shows a predilection for the surfaces of the pelvic viscera and has a high rate of recurrence after excision. Cystic mesotheliomas are not associated with asbestos exposure. We report a case of cystic mesothelioma of the peritoneum encasing the ovary, which presented as a cystic adnexal mass. As highlighted in this case and other recent reports, a cystic mesothelioma should not be referred to as a benign cystic mesothelioma, as it has potential for locoregional invasion, as well as distant nodal and serosal metastases. This tumour should be treated with aggressive cytoreductive surgery and appropriate chemotherapy. We review the differential diagnosis of this rare entity and suggest guidelines for its differentiation.
\end{abstract}

Keywords: cystic, mesothelioma, peritoneal

\section{INTRODUCTION}

Peritoneal mesotheliomas present with varied clinical, pathological and radiological features. Awareness of this may help both oncologists and radiologists narrow down the differential diagnoses and increase the chance of an accurate diagnosis. Cystic mesothelioma (CM) of the penitoneum is a rare neoplasm that occurs predominantly in women and tends to recur locally. CM typically arises from the mesothelium of the viscera in the pelvis, but may occur in other areas such as the intraperitoneal and retroperitoneal spaces. ${ }^{(1,2)}$ To our knowledge, there is a paucity of data in the literature regarding this entity. In this report, we present a case of $\mathrm{CM}$ and review the relevant literature on CM.

\section{CASE REPORT}

A 34-year-old woman presented with a one-year history of mild right iliac fossa pain. She had no history of vomiting, abdominal distension, change in bladder or bowel habits, or loss of appetite or weight. She gave a history of irregular menstruation for the past two years. Clinical examination revealed a right adnexal mass. Other systemic examinations were within normal limits. Before the patient presented to our institute, she had attended another hospital where resection of the lesion was planned. However, intraoperatively, the tumour was found to be unresectable. A biopsy was done, after which she was referred to our institute for further treatment.

Computed tomography (CT) of the abdomen revealed a well-defined lesion with peripheral enhancement, measuring approximately $2 \mathrm{~cm}$, in the right iliac fossa. The lesion involved the free margin of the mesentery and had a peripheral cystic component measuring $8 \mathrm{~cm}$ encasing the right ovary (Fig. 1). Ultrasonography (US) of the lesion showed a predominantly cystic lesion with multiple loculations encasing the right ovary (Fig. 2). The possibility of an ovarian malignancy was considered.

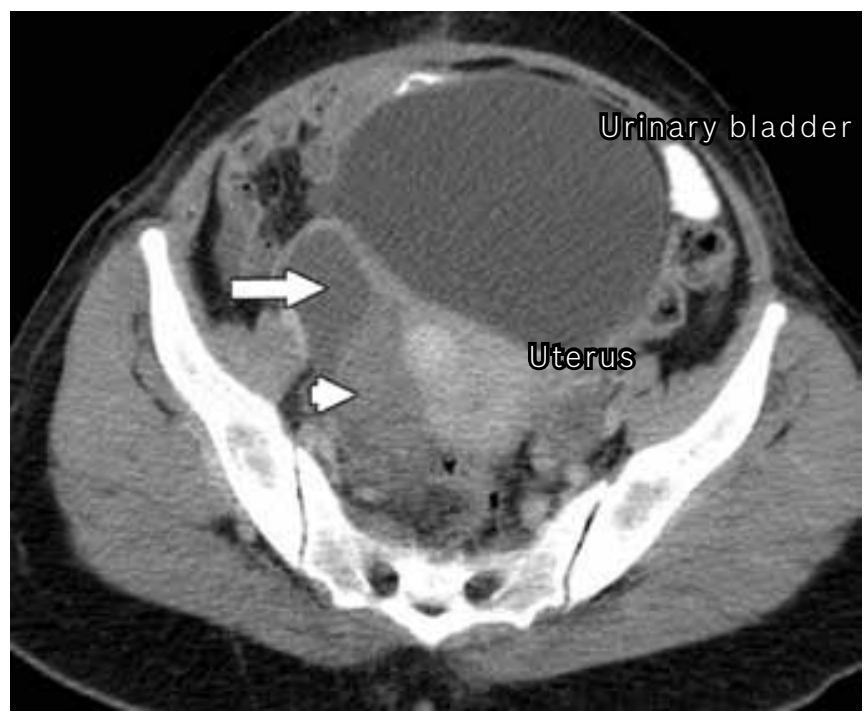

Fig. 1 Axial portal venous phase contrast-enhanced CT image of the pelvis shows a cystic lesion (arrow) encasing the right ovary (arrowhead)

Histopathology revealed a tumour that was composed of multiple well-defined cystic spaces separated by a loose and myxoid spindle-celled stroma. The tumour contained scattered inflammatory cells, foci of haemorrhage and fibrin deposition. The spaces contained pale pink fluid that did not stain well with Periodic-Acid Schiff Diastase (PASD). Some cysts appeared to have no distinct lining, whereas others were rimmed by flattened or plump cells. A few of the cysts were free in the lumen. The stromal cells had a variable appearance - enlarged and pleomorphic in some areas and relatively uniform elsewhere. Uniform appearance was observed, particularly at the location where the stromal cells extended into adjacent adipose tissue. The overall morphology was suggestive of a reactive myofibroblastic proliferation. Immunohistochemistry report

${ }^{1}$ Department of Medical Oncology, Christian Medical College, ${ }^{2}$ Department of Radiodiagnosis and Imaging, Christian Medical College, Tamil Nadu, India

Correspondence: Dr Parangama Chatterjee, Assistant Professor, Department of Radiodiagnosis and Imaging, Christian Medical College, Vellore 632004, Tamil Nadu, India. parangamadr@gmail.com 
revealed the following: cytokeratin and EMA positive (mostly in the cyst lining cells); desmin positive (mostly in the stromal cells); S-100 equivocal; calretinin, CD31 and CD34 negative. The histopathological appearance was consistent with a multicystic peritoneal mesothelioma with secondary pseudosarcomatous myofibroblastic proliferation.

The patient was treated with neoadjuvant chemotherapy with cisplatin and gemcitabine. After three cycles (i.e. nine weeks) of chemotherapy, repeat CT of the abdomen showed a significant increase in the size of the cystic component of the lesion, which had extended into the pouch of Douglas (Fig. 3). The progression of the disease suggested that the lesion was malignant. The patient underwent debulking surgery, and intraoperatively, we found a multiloculated cystic tumour adherent to the mid-rectum and involving the mesentery and omentum. Staging laparotomy, total abdominal hysterectomy, bilateral salpingo-oophorectomy, infracolic omentectomy and excision of the mass were performed. The result of the histopathological examination was consistent with residual disease, and the patient was treated with three more cycles of chemotherapy. Repeat CT after completion of chemotherapy showed complete resolution and no residual disease. At follow-up ten months later, the patient's disease was in remission with no residual disease detected in the abdomen.

\section{DISCUSSION}

Mesothelioma is a rare neoplasm that arises from the mesothelial cells lining the serosal membranes of body cavities. It is most commonly found in the pleural cavity, followed by the peritoneal cavity, either with or without pleural involvement. Peritoneal mesotheliomas are classified into three subtypes: malignant peritoneal mesothelioma, CM and well-differentiated papillary mesothelioma. The clinicopathological and imaging features of the three subtypes are presented in Table I. ${ }^{(1)}$ Except for malignant peritoneal mesotheliomas, the other peritoneal mesotheliomas are not related to asbestos exposure. ${ }^{(1)}$

Pathologically, CM typically consists of multiple grapelike clusters of mesothelium-lined cysts, although it may also be unilocular. ${ }^{(3)}$ The pathognomonic feature of these lesions is a thin-wall cystic structure located within a gelatinous-appearing mass. These thin-walled cysts are of variable size and preferentially located within the greater omentum and pelvis, and beneath the right hemidiaphragm. ${ }^{(4)}$ The major radiological differential diagnoses of CM are cystic lymphangioma, cystic epithelial neoplasm of the ovaries, tuberculosis and endometriosis. ${ }^{(4,5)}$ Other rare peritoneal neoplasms include primary peritoneal serous carcinoma, leiomyomatosis peritonealis disseminata, and desmoplastic small round cell tumour. ${ }^{(5)}$

$\mathrm{CM}$ is traditionally considered to be a benign neoplasm. ${ }^{(6)}$ However, in recent years, there have been case studies reporting malignant behaviour in these neoplasms. ${ }^{(7,8)}$ Our case report supports these studies in highlighting the potential malignant behaviour of CMs. The aim of treatment is complete disease
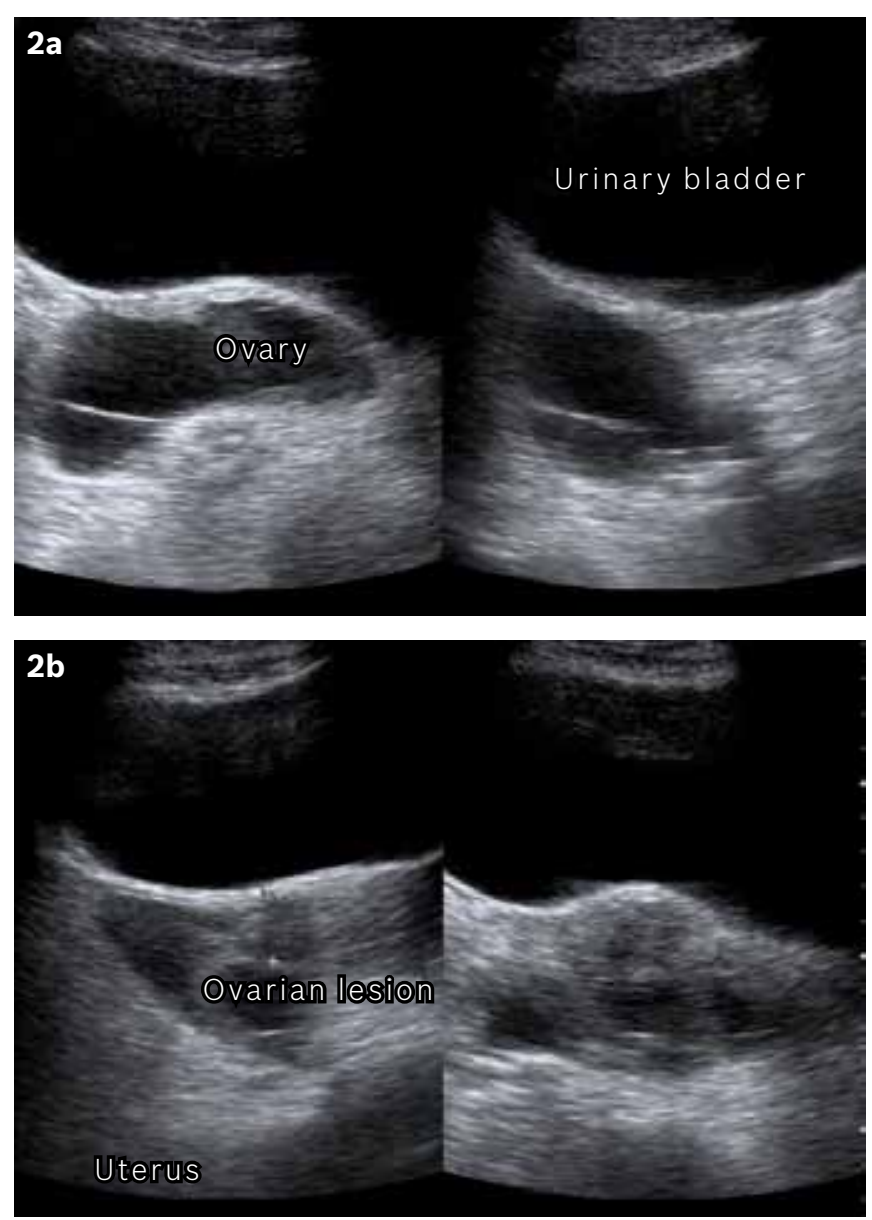

Fig. 2 US images show (a) a cystic lesion in the pelvis, posterior to the urinary bladder; and (b) a multiloculated cystic lesion in the pelvis.

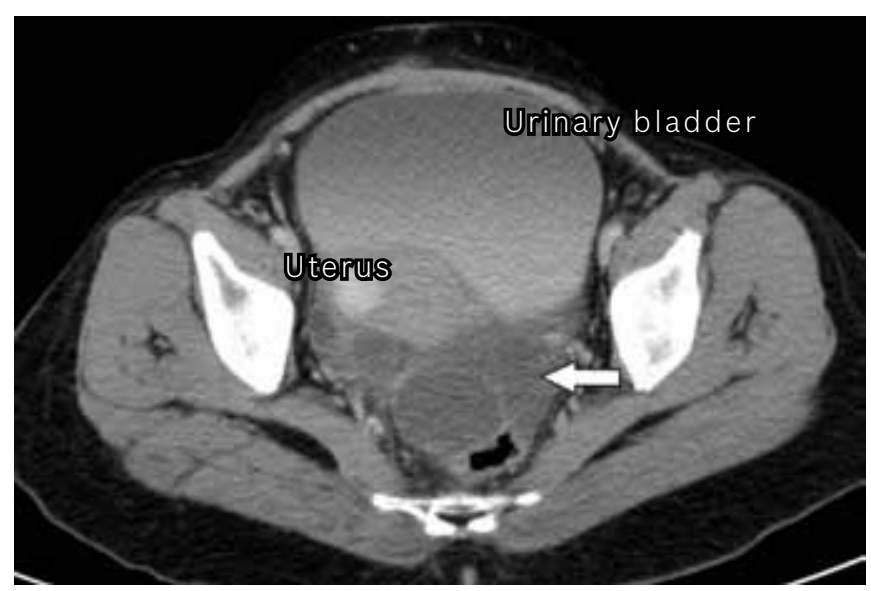

Fig. 3 Axial portal venous phase contrast-enhanced CT image of the pelvis, after nine weeks of chemotherapy, shows an increase in the size of the cystic lesion with multiple locules (arrow).

eradication, which can be achieved by adopting an aggressive approach, using cytoreductive surgery to remove the viable tumour. ${ }^{(7)}$ The use of chemotherapy, either neoadjuvant or adjuvant, to control microscopic residual disease will help patients with CM to remain symptom- and disease-free over an extended period of time after a single surgical intervention. Disease eradication in the form of adjuvant chemotherapy, post debulking surgery may prevent the transition of $\mathrm{CM}$ into an aggressive and fatal disease. 
Table I. Clinical, pathological and radiological features of subtypes of peritoneal mesotheliomas. ${ }^{(1)}$

\begin{tabular}{|c|c|c|c|}
\hline Parameter & $\begin{array}{l}\text { Malignant peritoneal } \\
\text { mesothelioma }\end{array}$ & Cystic mesothelioma & $\begin{array}{l}\text { Well-differentiated papillary } \\
\text { mesothelioma }\end{array}$ \\
\hline Risk factor & Asbestos exposure & $\begin{array}{l}\text { Previous abdominal surgery or pelvic } \\
\text { inflammatory disease }\end{array}$ & NA \\
\hline Age group & $\begin{array}{l}\text { Older men in the fifth and sixth } \\
\text { decades of life }\end{array}$ & Young to middle-aged women & Women of reproductive age \\
\hline Clinical course & Rapidly progressive & $\begin{array}{l}\text { Hormone sensitive (female sex } \\
\text { hormone receptors) }\end{array}$ & Indolent, malignant change is rare \\
\hline \multirow[t]{2}{*}{$\begin{array}{l}\text { Radiological (CT) } \\
\text { findings }\end{array}$} & $\begin{array}{l}\text { Wet appearance: } \\
\text { ascites, irregular or nodular } \\
\text { peritoneal thickening and } \\
\text { omental masses }\end{array}$ & $\begin{array}{l}\text { Multilocular cystic mass, multiple } \\
\text { unilocular thin-walled cysts or } \\
\text { unilocular cystic mass }\end{array}$ & $\begin{array}{l}\text { Peritoneal thickening, multiple } \\
\text { peritoneal nodules, omental infiltration } \\
\text { and ascites }\end{array}$ \\
\hline & $\begin{array}{l}\text { Dry appearance: } \\
\text { peritoneum-based masses, scalloping } \\
\text { or direct invasion of abdominal organs }\end{array}$ & & \\
\hline
\end{tabular}

CT: computed tomography

The risk of recurrence of the tumours is $50 \%-60 \%$, which is common, as far as malignancies associated with mesotheliomas are concerned.(7) While the overall median survival is about one year, a few cases of long-term survivors have been reported, with 19 years being the longest survival time reported. ${ }^{(8)}$ After the introduction of cytoreductive surgery, a significant increase in median survival was reported, with approximately half of the patients alive after five years. ${ }^{(7,8)}$

A close differential diagnosis in our case was ovarian malignancy. Cystic ovarian neoplasms occur as water-density masses in the pelvis; they may be thin-walled and difficult to distinguish from CM. While the average age of patients with cystic ovarian neoplasms is slightly greater than that of those with $\mathrm{CM}$, the significant overlap does not permit reliable differentiation. Ancillary findings with $\mathrm{CT}$, such as intratumoural mural nodules, ascites, or peritoneal mesenteric involvement, may suggest ovarian malignancy; however, these are not consistently demonstrated. Other differential diagnoses include lymphangioma and other mesenteric/omental cysts, ovarian teratoma, pseudomyxoma peritonei, cystic smooth-muscle tumours, visceral cysts, metastatic cystic mucinous neoplasms of the pancreas and endometriosis.

In conclusion, multicystic mesothelioma is a rare malignancy occuring in the abdomen. It has been described as a benign cystic mesothelioma or peritoneal inclusion cysts. Our case report highlights the possible malignant nature of some of these neoplasms, and underscores the importance of surgery, followed by chemotherapy, in patients with this malignant condition. Large follow-up studies are required to further define the malignant potential of these neoplasms. However, in view of the rarity of $\mathrm{CM}$ and hence, the lack of studies with a large cohort of patients, individual experience should be highlighted so as to disseminate knowledge about the natural history of cystic CM of the peritoneum.

\section{REFERENCES}

1. Park JY, Kim KW, Kwon HJ, et al. Peritoneal mesotheliomas: clinicopathologic features, CT findings, and differential diagnosis. AJR Am J Roentgenol 2008; 191:814-25.

2. O'Neil JD, Ros PR, Storm BL, Buck JL, Wilkinson EJ. Cystic mesothelioma of the peritoneum. Radiology 1989; 170:333-7.

3. Pickhardt PJ, Bhalla S. Primary neoplasms of peritoneal and sub-peritoneal origin: CT findings. Radiographics 2005; 25:983-95.

4. Sugarbaker P, Yan T, Zappa L, Haveric N, Brun E. Thin-walled cysts as a pathognomonic CT finding in cystic mesothelioma. Tumori 2008; 94:14-8.

5. Levy AD, Arnáiz J, Shaw JC, Sobin LH. From the archives of the AFIP: primary peritoneal tumors: imaging features with pathologic correlation. Radiographics 2008; 28:583-607.

6. Pass HI, Vogelzang NT, Hahn SM, Carbone M. Benign and Malignant Mesothelioma. In: De Vita VT, Hellman S, Rosenberg SA, eds. DeVita, Hellman and Rosenberg's Cancer: Principles \& Practice of Oncology. 8th ed. Philadelphia: Lippincott Williams \& Wilkins, 2008: 1839-40.

7. González-Moreno S, Yan H, Alcorn KW, Sugarbaker PH. Malignant transformation of "benign" cystic mesothelioma of the peritoneum. J Surg Oncol 2002; 79:243-51.

8. Sethna K, Mohamed F, Marchettini P, Elias D, Sugarbaker PH. Peritoneal cystic mesothelioma: a case series. Tumori 2003; 89:31-5. 